\title{
PENGARUH JUMLAH TAKSIRAN DAN UANG PINJAMAN TERHADAP LABA BERSIH PADA PT. PEGADAIAN (UPC) GURUN LAWEH
}

\author{
Muhammad Ikbal, Doni marlius \\ Akademi Keuangan dan Perbankan Padang \\ donimarlius@akbpstie.ac.id
}

\begin{abstract}
Theisie titled "effect and an estimated amount of money a loan to net income PT. Pegadaian (UPC) Gurun Laweh" this is the result of quanttative and statistical research objectvely through calculation based an the figurer.Research shows that net income is affected while the estimated number of loan money did not affect net income PT.Pegadaian (UPC) Gurun Laweh which can be seen from the regression analysis conducted.
\end{abstract}

Keyword: Examination, Loan Money, Net Income

\section{Pendahuluan}

Latar Belakang

Krisis ekonomi jilid II tahun 20072008 yang berawal dari kebangkrutan perusahaan finansial di Amerika Serikat karena kredit kepemilikan rumah yang gagal bayar memberikan dampak luas bagi masyarakat dunia. Hal ini karena Amerika Serikat menjadi tujuan ekspor bagi pelaku usaha baik dari Indonesia maupun negara lainnya. Dampak bagi perekonomian Indonesia adalah semakin melambungnya harga bahan baku impor, produk elektronik, computer, hingga barang kebutuhan rumah tangga yang harganya melambung. Meskipun pemerintah telah menurunkan tarif BBM, namun harga-harga kebutuhan pokok semakin meningkat, daya beli konsumen semakin menurun, terjadi peningkatan beban biaya bagi pelaku usaha.
Salah satu upaya pemerintah untuk menyehatkan perekonomian nasional adalah dengan cara penyaluran dana dalam bentuk kredit. Kredit tersebut dapat diberikan kepada masyarakat atau wirausahawan yang memerlukan untuk mengembangkan usahanya..

PT Pegadaian adalah salah satu Badan Usaha Milik Negara (BUMN) yang bergerak dalam usaha menyalurkan dana atas dasar hukum gadai dengan sifat yang khas yaitu menyediakan pelayanan bagi pemanfaatan umum dan sekaligus memupuk keuntungan berdasarkan prinsip pengelolaan bisnis. Secara umum pengertian usaha gadai menurut kasmir (2010:262) adalah kegiatan menjaminkan barang-barang berharga kepada pihak tertentu, guna memperoleh sejumlah uang dan barang yang dijaminkan akan ditebus kembali sesuai dengan perjanjian antara nasabah dengan lembaga 
gadai. Menurut Hasan (2003:246) dalam Ensiklopedia Indonesia, disebutkan bahwa gadai atau hak gadai adalah hak atas benda terhadap benda bergerak milik si berhutang yang diserahkan ketangan si berhutang yang diserahkan ketangan si pemberi utang sebagai jaminan pelunasan utang si berutang tersebut Laba bersih dari suatu kegiatan perusahaan sangatlah penting karena akan menentukan perusahaan tersebut sehat atau tidaknya, dalam kegiatan usaha gadai di PT. Rumusan masalah

Berdasarkan pernyataan diatas maka rumusan masalah pada penelitian ini adalah

jumlah taksiran dan uang pinjaman terhadap laba bersih pada PT. Pegadaian (UPC) Gurun laweh?

\section{Tinjauan pustaka PT. Pegadaian (UPC) Gurun laweh}

PT. Pegadaian (UPC) Gurun laweh yaitu Dasar hukum kegiatan pegadaian atau usaha gadai yaitu Peraturan Pemerintah (PP) Nomor 10 Tahun 1990 tentang Perusahaan Umum Pegadaian. Dalam PP tersebut, pegadaian atau usaha gadai dimaknai sebagai kegiatan menjaminkan barang-barang berharga pada piahak tertentu, guna mendapatkan jumlah uang senilai barang yang dijaminkan akan ditebus sesuai dengan kesepakatan dengan lembaga gadai.

\section{Gambaran umun}

Sejarah pegadaian dimulai pada saat pemerintahaan penjajahan belanda (VOC) mendirikan "Bank Van Leening" yaitu lembaga keuangan yang memberikan kredit dengan sistem gadai. Lembaga ini
Pegadaian uang pinjaman akan didapatkan setelah barang yang akan dijaminkan ditaksir telebih dahulu, yang dilakukan sesuai prosedur PT. Pegadaian. Dibeberapa perusahaan peminjaman uang dengan menggunakan barang jaminan. Jaminan tersebut di taksir dan uang pinjaman barulah akan cair, banyak dari perusahaan tersebut mengalami persentase keuntungan yang berbeda tergantung taksiran dan uang pinjaman.

pertama kali didirikan di Batavia pada tanggal 20 Agustus 1746.

Ketika Inggris mengambil alih kekuasaan Indonesia dari tangan Belanda (1811-1816) "Bank Van Leening" milik pemerintah dibubarkan, masyarakat diberi keleluasan untuk mendirikan usaha pegadaian asal mendapat lisensi dari pemerintahan Negara setempat (liencenti stelsel). Namun metode tersebut berdampak buruk, pemegang lisensi menjalakan praktek rentenir atau lintah darat yang dirasakan kurang menguntungkan pemerintah berkuasa (Inggris). Oleh karna itu, metode "liencentie stelsel" diganti menjadi "pacth stelsel" yaitu pendirian pegadaian diberikan kepada umum yang mampu membayarkan pajak yang tinggi kepada pemerintah.

Pada saat Belanda berkuasa kembali, pola atau metode "pacth stelsel" tetap dipertahankan dan menimbulkan dampak yang sama dimana pemengang hak ternyata banyak melakukan penyelewengan dalam menjalankan bisnisnya. Selanjutnya pemerintah Hindia Belanda menerapkan apa yang disebutkan dengan "cultuur stelsel" dimana dalam kajian tentang pegadaian, saran yang dikemukakan 
adalah sebaiknya kegiatan pegadaian ditangani sendiri oleh pemerintah agar dapat memberikan perlindungan dan manfaat yang lebih besar bagi masyarakat.berdasarkan hasil penelitiaan tersebut,pemerintah Hindia Belanda mengeluarkan statsblas (Stbl) No 131 tanggal 12 Maret 1901 yang mengatur bahwa usaha pegadaian merupakan monopoli pemerintahan dan tanggal 1 April 1901 didirikan pegaadaaian Negara pertama di Sukabumi (Jawa Barat), selanjutnya setiap tanggal 1 April diperingati hari ulang tahun pegadaian.

Pada masa pendudukan Jepang, gedung kantor pusat jawatan pegadaian yang terletak di jalan Kramat Raya 162 dijadikan tempat tawanan perang dan kantor pusat jawatan pegadaian dipindahkan ke jalan Kramat Raya no 132. Tidak banyak perubahan yang terjadi pada masa pemerintahan Jepang, baik dari sisi kebijakan maupun struktur organisasi jawatan pegadaian jawatan pegadaian dalam bahasa jepang disebut "Stiji Eigeikyuku" pimpinan jawatan pegadaian dipegang oleh orang Jepang yang bernama Ohni-San dengan wakil nya orang pribumi yang bernama M.Saubari.

Pada masa awal pemerintahan Republik Indonesia, kantor jawatan pegadaian sempat pindah ke Karang Anyar (Kebumen) karena situasi perang yang lain kian memanas agen militer Belanda yang kedua memaksa kantor jawatan pegadaian dipindah lagi ke Magelang. Selanjutnya pasca perang kemerdekaan kantor jawatan pegadaian kembali lagi ke Jakarta dan pegadaian kembali dikelola oleh pemerintah Indonesia. Dalam masa ini pegadaian sudah berapa kali berubah status, yaitu sebagai
Perusahaan Negara (PN) sejak 1 januari 1961, kemudian berdasarkan PP.No.7/1969 menjadi perusaahan jawatan (PERJAN), selanjutnya berdasarkan PP.No.10/1990 (yang diperbarui dengan PP.No./103/2000) berubah lagi menjadi perusahaan umum (PERUM). Hingga pada tahun 2011, berdasarkan peraturan republik Indonesia no 51 tahun 2011 tanggal 13 Desember 2011, bentuk badan hukum pegadaian berubah menjadi perusahaan perseroan (Persero).

\section{Pengertian Pegadaian}

Dasar hukum kegiatan pegadaian atau usaha gadai yaitu Peraturan Pemerintah (PP) Nomor 10 Tahun 1990 tentang Perusahaan Umum Pegadaian. Dalam PP tersebut, pegadaian atau usaha gadai dimaknai sebagai kegiatan menjaminkan barang-barang berharga pada piahak tertentu, guna mendapatkan jumlah uang senilai barang yang dijaminkan akan ditebus sesuai dengan kesepakatan dengan lembaga gadai.

Adapun pegadaian menurut Undang-undang Hukum Perdata (KUHP) Pasal 1150 disebutkan bahwa gadai adlah suatu hak yang diperoleh seseorang yang berpiutang atas suatu barang bergerak, yang diserahkan kepadanya oleh seorang yang memiliki hutang atau oleh seorang lain atas namanya, dan yang memberikan kekuasaan kepada orang yang berpiutang untuk mengambil pelunasan dari barang tersebut diprioritaskan dari pada orang yang berpiutang lainya, dengan pengecualian biaya untuk melelang barang tersebut dan biaya yang telah dikeluarkan untuk menyelamatkan setelah barang itu digadaikan 


\section{Taksiran}

Menaksir adalah menentukan nilai atau harga perkiraan tertentu yang akan dijadikan jaminan yang didasarkan pada harga jadi, pasar

\section{Metode penelitian}

Metode pengumpulan data

a. Penelitian lapangan (field research)

Yaitu suatu metode penelitian dengan cara mendatang langsung ke dan peraturan yang berlaku untuk masa tertentu, ketentuan taksiran.

2. Uang pinjaman

Menurut Sitio (2001:151) uang pinjaman adalah sejumlah uang yang dikeluarkan oleh suatu lembaga perusahaan yang menjadi objek kajian

b. Studi pustaka (library research) Yaitu dengan melakukan penelitian dengan beberapa buku ilmiah dan tulisan

\section{Hasil dan pembahasan}

Tabel 3.2

Pada tahun 2016

\begin{tabular}{|c|c|c|c|c|c|c|c|c|c|}
\hline Bulan & Taksiran(x1) & $\begin{array}{c}\text { Uang } \\
\text { Pinjaman(x2) }\end{array}$ & $\begin{array}{c}\text { Sewa } \\
\operatorname{Modal}(y)\end{array}$ & $(\mathbf{x 1}) 2$ & $(\mathrm{x} 2) 2$ & $(y) 2$ & X1.X2 & X1.Y & X2.Y \\
\hline Januari & 628.877317 & 517.140 .000 & 47.110 .600 & 395.486 .679 .837 .118 .000 & 267.433 .779 .600 .000 .000 & 2.219 .408 .632 .360 .000 & 325.217 .615 .713 .380 .000 & 29.626 .787 .730 .260 .200 & 24.362 .775 .684 .000 .000 \\
\hline Februari & 707.322 .688 & 569.310 .000 & 51.227 .400 & 500.305 .384 .959 .545 .000 & 324.113 .876 .100 .000 .000 & 2.624 .246510 .760 .000 & 402.685 .879 .505 .280 .000 & 36.234 .302 .267 .251 .200 & 29.164.271.094.000.000 \\
\hline Maret & 636.707 .003 & 486.020 .000 & 44.116 .500 & 405.395 .807 .669 .242 .000 & 236.215 .440 .400 .000 .000 & 1.946 .265572 .250 .000 & 309.452337 .598 .060 .000 & 28.089 .284 .497 .849 .500 & 21.441 .501 .330 .000 .000 \\
\hline April & 820.204591 & 630.140 .000 & 55.695 .300 & 672.735571 .097 .477 .000 & 397.076 .419 .600 .000 .000 & 3.101 .966 .442 .090 .000 & 516.843 .720 .972 .740 .000 & 45.681 .540 .757 .122 .300 & 35.095 .836 .342 .000 .000 \\
\hline Mai & 672.708 .918 & 503.870 .000 & 45.160 .400 & 452.537 .288 .356 .731 .000 & 253.884 .976 .900 .000 .000 & 2.039 .461 .728 .160 .000 & 338.957 .842 .512 .660 .000 & 30.379 .803 .820 .447 .200 & 22.754 .970 .748 .000 .000 \\
\hline Juni & 606.802 .928 & 445.410 .000 & 40.273 .000 & 368.209 .793 .429 .373 .000 & 198.390 .068 .100 .000 .000 & 1.621 .914529 .000 .000 & 270.276 .092 .160 .480 .000 & 24.437 .774 .319344 .000 & 17.937 .996 .930 .000 .000 \\
\hline Juli & 544.485 .822 & 407.600 .000 & 37.088 .300 & 296.464 .810 .359 .016 .000 & 166.137 .760 .000 .000 .000 & 1.375 .541 .996 .890 .000 & 221.932 .421 .047 .200 .000 & 20.194 .053 .512 .082 .600 & 15.117 .191 .080 .000 .000 \\
\hline Agustus & 829.689 .887 & 621.100 .000 & 56.327 .100 & 688.385308 .590 .073 .000 & 385.765 .210 .000 .000 .000 & 3.172 .742 .194 .410 .000 & 515.320 .388 .815 .700 .000 & 46.734 .025 .234 .037 .700 & 34.984 .761 .810 .000 .000 \\
\hline September & 595.746 .465 & 438.550 .000 & 39.939 .900 & 354.913 .850 .559 .996 .000 & 192.326 .102 .500 .000 .000 & 1.595 .195 .612 .010 .000 & 261.264 .612 .225 .750 .000 & 23.794.054.237.453.500 & 17.515 .643 .145 .000 .000 \\
\hline Oktober & 768.198549 & 569.840 .000 & 51.719 .200 & 590.129 .010 .685 .705 .000 & 324.717 .625 .600 .000 .000 & 2.674 .875 .648 .640 .000 & 437.750 .261 .162 .160 .000 & 39.730 .614 .395 .440 .800 & 29.471 .668 .928 .000 .000 \\
\hline November & 611.567 .072 & 450.080 .000 & 40.937 .700 & 374.014 .283 .554 .653 .000 & 202.572 .006 .400 .000 .000 & 1.675 .895 .281 .290 .000 & 275.254 .107 .765 .760 .000 & 25.036 .149 .323 .414 .400 & 18.425 .240 .016 .000 .000 \\
\hline Desember & 826.076 .665 & 652.880 .000 & 58.744 .600 & 682.402 .656 .457 .522 .000 & 426.252 .294 .400 .000 .000 & 3.450 .928 .029 .160 .000 & 539.328 .933 .045 .200 .000 & 48.527 .543 .254 .759 .000 & 38.353 .174 .448 .000 .000 \\
\hline$\sum$ Total & 8.248.387.905 & 6.291 .940 .000 & 568.340 .000 & 5.780 .980 .445 .556 .450 .000 & 3.374 .885559 .600 .000 .000 & 27.498.442.177.020.000 & 4.414.284.212.524.370.000 & 398.465 933.349.462000 & 304.625.031.555.000.000 \\
\hline
\end{tabular}


$\sum x_{1}^{2}=\sum x_{1}^{2}-{\frac{\left(\sum x_{1}\right)^{2}}{n}}^{2}=$

$5.780 .980 .445 .556 .450 .000-\frac{8.248 .387 .905^{2}}{12}$

111.321 .859 .610 .595 .000

$\sum x_{2}{ }^{2}=\sum x_{2}{ }^{2}-\frac{\left(\sum x_{2}\right)^{2}}{n}$

$3.374 .885 .559 .600 .000 .000-\frac{6.291 .940 .000^{2}}{12}$

75.843.145.966.666.800

$\sum y^{2}=\sum y^{2}-{\frac{\left(\sum y\right)^{2}}{n}}^{2}$

27.498.442.177.020.000 $-\frac{568.340 .000^{2}}{12}$

580.912 .543 .686 .668

$\sum x_{1} y=\sum x_{2} y-\frac{\sum x_{2} \times \sum y}{n}$

398.465.933.349.462.000 $-\frac{304.625 .031 .555 .000 .000}{12}$

7.808.534.855.487.300

$\sum x_{2} y=\sum x_{2} Y-\frac{\sum x_{2} \times \sum y}{n}$

$304.625 .031 .555 .000 .000-\frac{6.291 .940 .000 \times 568.340 .000}{12}$

6.628 .266 .588 .333 .310

$\sum x_{1} x_{2}=\sum x_{1} x_{2}-\frac{\sum x_{1} \sum x_{2}}{n}$

$4.414 .284 .212 .524 .370 .000-\frac{8.248 .387 .905 \times 6.291 .940 .000}{12}$

89.420 .729 .608 .895 .000

Sehingga:

$b_{1}=\frac{\left[\left(\sum x_{2}^{2} \times \sum x_{1} y\right)-\left(\sum x_{2} y \times \sum x_{1} x_{2}\right)\right]}{\left[\left(\sum x_{1}^{2} \times \sum x_{2}^{2}\right)-\left(\sum x_{1} \times x_{2}\right)^{2}\right]}$

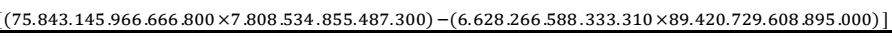
$(111.321 .859 .610 .595 .000 \times 75.843 .145 .966 .666 .800)-(89.420 .729 .608 .895 .000)^{2}$

$=-0,001$

$b_{2}=\frac{\left[\left(\sum x_{1}{ }^{2} \times \sum x_{2} y\right)-\left(\sum x_{1} y \times \sum x_{1} x_{2}\right)\right]}{\left[\left(\sum x_{1}{ }^{2} \times \sum x_{2}{ }^{2}\right)-\left(\sum x_{1} \times x_{2}\right)^{2}\right]}$

$[(111.321 .859 .610 .595 .000 \times 6.628 .266 .588 .333 .310)-(7.808 .534 .855 .487$

$[(111.321 .859 .610 .595 .000 \times 75.843 .145 .966 .666 .800)-(89.42$

$=0,089$

$a=\frac{\left(\sum y\right)-\left(b_{1} \times \sum x_{1}\right)-\left(b_{2} \times \sum x_{2}\right)}{n}$

$(568.340 .000)-(0,001 \times 8.248 .387 .905)-(0,089 \times 6.291 .940 .000)$

$=1612683,530$

$\mathrm{Y}=\mathrm{a}+\mathrm{b} 1 \mathrm{X} 1+\mathrm{b} 2 \mathrm{X} 2$

$\mathrm{Y}=1612683,53-0,001 \times 1+0,089 \times 2$

Interpresentasi koefisien regresi

a. Jika x1 dan x2 sama dengan nol

maka $y=1612683,53$,

b. Jika x1 naik 1 satuan dan x2 sama dengan nol maka y turun $-0,001$, maka dapat disimpulkan jumlah taksiran tidak berpengaruh terhadap laba bersih yang dihasilkan PT. Pegadaian (UPC) Gurun Laweh

c. Jika x2 naik 1 satuan dan x1 sama dengan nol maka y naik sebesar 0,089, maka dapat disimpulkan bahwa uang pinjaman akan berpengaruh terhadap laba yang akan dihasilkan PT. Pegadaian (UPC) Gurun Laweh

\section{Kesimpulan dan saran Kesimpulan}

berdasarkan analisa yang dilakukan berdasarkan analisa regresi berganda dapat diketahui bahwa uang pinjaman mempunyai pengaruh 
terhadap laba bersih sedangkan taksiran tidak punya pengaruh terhadap naik atau turunya laba bersih

\section{Saran}

a. Walaupun jumlah taksiran tidak berpengaruh terhadap laba bersih PT. Pegadaian (UPC) Gurun Laweh tetap memperhatikan jumlah taksiran sebagai jaminan dari barang gadai apabila nasabah tidak mampu untuk membayar.

b. Meningkatkan uang pinjaman dari hasil taksiran akan membuat nasabah tertarik.

c. Lebih menekankan sewa modal agar bisa menarik nasabah yang lebih banyak.

\section{Daftar pustaka}

Kasmir, 2010 ， Dasar - Dasar Perbankan, PT. Raja Grafindo Persda, Jakarta:

Lumbatorum, 2001, Dasar - Dasar Akuntansi Keuangan, PT. Gramedia Media Saran Indonesia Jakarta.

Hasan, 2003, Pegadaian, Akbar Media Suara, Jakarta.

Sugiyono, 2004, Statistika Untuk Penelitian Cetakan kedelpan. Albeta Bandung.

Triandaru, S., Budisantoso, T, 2006 Bank dan Lembaga Keuangan Lain, Salemba Empat, Jakarta.
Damanhur, 2006, Leli Darwina, Jurnal Aplikasi Manajemen, Jakarta. Dikti, Jakarta.

Triandaru,Sigit. 2006, Budisantoso, Totok, Bank Dan Lembaga Keuangan Lain. Salemba empat, Yogyakarta.

Hartanto, Dicki, 2012, Bank Dan Lembaga Keuangan Lain.: Aswaja Pressindo, Yogyakarta .

Irawan wae, "contoh soal regresi berganda", diakses dari http://irawanwae.blogspot.co. id, pada tanggal 20 Februari pukul 11:00.

Wikipedia, "pegadaian perusahaan", diakses dari https://id.m.wikipedia.org/wi ki/Pegadaian_(perusahaan), pada tanggal 25 Januari pukul 20:30. 